\title{
PEMETAAN TINGKAT BAHAYA LONGSOR DI JALAN LINTAS \\ KECAMATAN LEMBAH GUMANTI - KECAMATAN PANTAI CERMIN KABUPATEN SOLOK
}

\author{
Ratna Husin Nasution ${ }^{1}$, Triyatno ${ }^{2}$, dan Endah Purwaningsih ${ }^{3}$ \\ Program Studi Geografi \\ Fakultas Ilmu Sosial, Universitas Negeri Padang \\ Email: $\underline{\text { ratnanasution1@gmail.com }}$
}

\begin{abstract}
ABSTRAK
Penelitian ini bertujuan untuk mengetahui kondisi karakteristik lahan dan tingkat bahaya longsor di daerah penelitian. Hasil penelitian sebagai berikut: 1. Karakteristik lahan: a) iklim: curah hujan $2.224 \mathrm{~mm} /$ tahun, b) geologi: struktur lapisan batuan dengan bentuk miring dan miring bergelombang, c) geomorfologi: bentuklahan pegunungan dan perbukitan, satuan bentuklahan lereng kaki gunung api, kemiringan lereng yang sangat curam $43 \%$ dan curam $40 \%$ dengan panjang lereng yang sedang $45 \mathrm{~m}$, panjang $100 \mathrm{~m}$, sangat panjang $210 \mathrm{~m}$, bentuk lereng lurus, cembung, cekung, bervariasi cembung cekung, d) tanah: tekstur tanah lempung berpasir dan pasir berdebu, struktur tanah remah, gumpal, bukit tunggal, konsistensi tanah sangat gembur, lepaslepas, permeabilitas tanah sangat cepat $21 \mathrm{~cm} / \mathrm{jam}$ dan cepat 7,09 cm/jam e) hidrologi: kedalaman muka air tanah $<500 \mathrm{~cm} \mathrm{f}$ ) penggunaan lahan: semak belukar/alang-alang, tegalan/kebun campuran dan pemukiman. 2. Tingkat bahaya longsor: a) sedang: Pada daerah Batang Hari, Aia Dingin, Cubadak, Lolo. b) Tinggi: Pada daerah Aia Ampu.
\end{abstract}

Kata kunci : Lahan, Longsor.

\begin{abstract}
This research of aims are determine the condition of land characteristics and the level of landslide hazard in the research area. The sample of this research is purposive sampling, the sample is taken in accordance with the research objectives. The research show as follows: 1. Land characteristics: a) climate: rainfall $2.224 \mathrm{~mm} /$ year, b) geology: rock layer structure with an oblique shape and tilted wavy, c) geomorphology: form of mountainous and hilly land, landform unit of the foot slope volcano, very steep slope of $43 \%$ and steep $40 \%$ with medium slope length 45 $\mathrm{m}$, length $100 \mathrm{~m}$, very long $210 \mathrm{~m}$, and the shape of the slope is straight, convex, concave, irregular. d) soil: soil texture sandy loam, and dusty sand, structure of land crumb,lumpy, single hill, consistency of land very loose, loose, soil permeability very fast $21 \mathrm{~cm} / \mathrm{h}$ and fast 7,09 $\mathrm{cm} / \mathrm{h}$ e) hydrology: groundwater depth $<500 \mathrm{~cm}$ f) land use: shrubs / reeds and moor / seasonal gardens and settlement 2. the level of landslide hazard: a) medium: At Batang Hari, Aia Dingin, Cubadak, Lolo. b) high: At Aia Ampu.
\end{abstract}

Keyword: Land, Hazard.

\footnotetext{
1 Mahasiswa Geografi, FIS UNP

2,3 Dosen Geografi, FIS UNP
} 


\section{PENDAHULUAN}

Indonesia merupakan salah satu negara yang rawan akan bencana. Menurut UU No. 24 Tahun 2007 tentang Penanggulangan Bencana, bencana ialah peristiwa atau rangkaian peristiwa yang mengancam dan mengganggu kehidupan dan penghidupan masyarakat yang disebabkan, baik oleh faktor alam dan/atau faktor non alam maupun faktor manusia sehingga mengakibatkan timbulnya korban jiwa manusia, kerusakan lingkungan, kerugian harta benda, dan dampak psikologis. Bencana dapat dibedakan menjadi tiga antara lain bencana alam, bencana non alam dan bencana sosial.

Menurut Guillard \& Zezere, (2012) Dalam berbagai model penentuan erosi dan longsor, faktor kelerengan dimasukkan dalam unsur utama. Menurut Ponziani et al, 2012; Lepore, (2013) Kondisi tanah yang labil dengan lereng yang curam adalah daerah yang rawan longsor, apabila terjadi cuaca ekstrim berupa curah hujan yang tinggi maka kemungkinan akan terjadi longsor. Peningkatan curah hujan berkorelasi positif terhadap kelembaban tanah sebelum terjadi longsor.

Sementara itu menurut Kim, et al. (2015) faktor yang paling berpengaruh terhadap kejadian longsor adalah hujan harian maksimum, 5 hari hujan maksimum, jumlah hari dengan hujan lebih besar dari $120 \mathrm{~mm}$, kelerengan, elevasi, kedalaman tanah, drainase tanah, jenis tanah, dan tipe hutan. Selain dari faktor alami, faktor manusia juga dapat berpengaruh. Kegiatan pembangunan dalam suatu daerah aliran sungai (DAS) dapat mempengaruhi rasio kejadian longsor (Y. Chen et al., 2013), demikian halnya dengan pembuatan konstruksi jalan (Gorsevski et al., 2003) dan perubahan penggunaan lahan (Chen dan Huang, 2013).

Bahaya longsor tidak selalu dapat ditanggulangi dengan penanaman pohon, terutama untuk longsor dalam (deep landslide) yang diakibatkan oleh intensitas hujan yang tinggi dan juga gempa bumi. Demikian juga pada lahan dengan tanah yang tidak stabil yang mendukung sedikit pepohonan seperti halnya timbunan tanah vulkanik. Risiko longsor meningkat sejalan dengan besarnya kelerengan (Forbes dan Broadhead, 2013; Gorsevski et al., 2003; Kim et al., 2015; Pereira et al., 2013).

Menurut Gorsevski, et al. (2003) longsor yang diakibatkan oleh konstruksi jalan tidak hanya terjadi pada lereng terjal tetapi juga terjadi pada lereng datar dan bentang lahan yang berbentuk cembung (convex).

Seperti halnya hasil penelitian Hua-Xi dan Kun-Long (2014) yang menunjukkan bahwa dengan menggunakan informasi geomorfologi yang detil memberikan akurasi yang lebih baik. 
Hal ini diperlukan untuk mengetahui pentingnya pemilihan data dalam perencanaan detil sehingga memberikan hasil yang lebih aplikatif di lapangan.

Menurut data bencana dari BNPB (Badan Nasional Penanggulangan Bencana) pada tahun 2014 bencana longsor sering terjadi di Indonesia, khusus daerah Sumatera Barat untuk tahun 2015 telah banyak terjadi bencana longsor diantaranya: di Kabupaten Agam, Kabupaten Tanah Datar, Kota Sawahlunto, Kabupaten Padang Pariaman, Kabupaten Dharmasraya dan yang paling banyak terjadi longsor berada di Kabupaten Solok dan Kabupaten Solok Selatan termasuk di dalamnya jalan lintas Kecamatan Lembah Gumanti Kecamatan Pantai Cermin.

Ruas jalan lintas Kecamatan Lembah Gumanti - Kecamatan Pantai Cermin terdapat jalan akses yang melalui daerah perbukitan. Daerah tersebut sering mengalami bencana longsor. Di sisi bawah dari jalan terdapat lereng yang memliki kemiringan lereng yang sangat curam dan memiliki potensi longsor yang tinggi. Sehingga wilayah ini menjadi daerah bencana longsor, terutama Kabupaten Solok meliputi: Kecamatan Kabung, Kecamatan. Tigo Lurah, Kecamatan X Koto Singkarak, Kecamatan IX Koto Sungai Lasi, Kecamatan Lembah Gumanti, Kecamatan Pantai Cermin, Kecamatan Payung Sekaki,
Kecamatan Bukit Sundi dan Kecamatan X Koto Diatas terkena bencana longsor.

Berdasarkan kondisi ruas jalan lintas Kecamatan Lembah Gumanti Kecamatan Pantai Cermin yang melalui daerah perbukitan dengan jurang dan tebing di sepanjang jalan yang suatu saat bisa saja terjadi longsor, maka akan menjadi penghambat bagi para pengguna jalan lintas Kecamatan Lembah Gumanti - Kecamatan Pantai Cermin. Sebagaimana daerah dengan tingkat bahaya longsor yang tinggi berada pada daerah kawasan perhubungan lalu lintas. Sehingga dengan adanya kerusakan lingkungan berupa bahaya longsor akan mempengaruhi efektivitas aksesibilitas yang terjadi di kawasan perhubungan tersebut, maka peneliti mengangkat judul penelitian mengenai "Pemetaan Tingkat Bahaya Longsor di Jalan Lintas Kecamatan Lembah Gumanti Kecamatan Pantai Cermin". Penelitian ini bertujuan untuk mempermudah dalam mengetahui persebaran tingkat bahaya longsor melalui gambaran visual berupa peta mengenai keadaan spasial daerah bahaya longsor di jalan lintas Kecamatan Lembah Gumanti Kecamatan Pantai Cermin.

\section{METODE PENELITIAN}

Penelitian ini digolongkan menjadi penelitian kuantitatif. Pendekatan kuantitatif adalah 
penelitian yang banyak menuntut penggunaan angka, mulai dari pengumpulan data, penafsiran data serta penampilan hasilnya.

Satuan pemetaan dalam penelitian ini adalah satuan lahan. Satuan lahan diperoleh melalui overlay peta satuan bentuklahan dengan peta lereng, tanah, geologi dan penggunaan lahan. Setiap satuan lahan yang bervariasi akan diambil satu untuk mewakili sebagai sampel. Pengambilan sampel dilakukan dengan teknik purposive sampling. Penentuan tingkat bahaya longsor dilihat dari satuan lahan yang dekat dengan aktivitas manusia dan jalan raya sehingga pengambilan sampel juga memperhatikan aspek tersebut.

Analisis bahaya untuk menentukan tingkat bahaya longsor digunakan formula yang dikemukakan oleh Dibyosaputro dalam Karim (2012) yaitu sebagai berikut :

$$
I=\frac{c-b}{k}
$$

Dimana :

$I=$ besar interval kelas

$c=$ jumlah harkat terkoreksi tertinggi (7.8)

$b=$ jumlah harkat terkoreksi terendah (1.95)

$k=$ jumlah kelas yang diinginkan

Bila jumlah kelas yang diinginkan (k) adalah 4, Jumlah variabel ada 13 ,

$$
I=\frac{7.8-1.95}{4}=1,46
$$

Dari persamaan di atas, maka interval tingkat bahaya longsor Zuidam dan Concelado dalam Hermon (2012) dapat dilihat Tabel 1 berikut :

Tabel 1. Tingkat Bahaya Longsor
\begin{tabular}{|c|c|c|}
\hline Kelas & Interval & Tingkat bahaya \\
\hline I & $<1.46$ & Rendah \\
\hline II & $1.46-2.92$ & Sedang \\
\hline III & $2.92-4.38$ & Tinggi \\
\hline IV & $>4.38$ & Sangat Tinggi \\
\hline
\end{tabular}
Sumber: Zuidam dan Concelado (1979) dalam Hermon
(2012) dengan modifikasi.

\section{HASIL DAN PEMBAHASAN}

\section{A. Karakteristik lahan}

Menurut Sipayung et al., (2014) bahwa nilai ambang curah hujan yang berpotensi menyebabkan longsor akan berbeda pada setiap daerah, dan akan berpengaruh lebih besar pada daerah yang rentan longsor dibandingkan dengan daerah yang tidak rentan longsor meskipun dengan curah hujan yang sama.

Seperti dijelaskan oleh Putra et al., (2018) bahwa curah hujan merupakan pemicu terjadinya longsor. Berdasarkan observasi di lapangan merupakan daerah yang terletak pada daerah beriklim tropis dan mempunyai curah hujan cukup tinggi dengan $2224 \mathrm{~mm} /$ tahun. Sehingga hal ini menyebabkan longsor yang terjadi terus berlangsung di wilayah sepanjang jalan lintas Kecamatan Lembah Gumanti - Kecamatan Pantai Cermin.

Struktur lapisan batuan daerah penelitian berbentuk miring 
bergelombang dan berbentuk miring. Batuan daerah penelitian merupakan batuan yang berasal dari aktivitas gunung api yang berupa erupsi magma yang keluar dari perut bumi kemudian mengalami pendinginan dan mengeras menjadi batu sehingga tanah endapan yang berasal dari gunung api merupakan tanah yang sangat rentan dan labil terhadap longsor. Faktor geologi yang mempengaruhi terjadinya gerakan tanah adalah struktur geologi, sifat batuan, hilangnya perekat tanah karena proses erosi.

Bentuklahan berdasarkan hasil penelitian batuan daerah penelitian merupakan pegunungan dan perbukitan yang terdiri dari bentuk lahan denudasional, dan karst.

Satuan bentuklahan berdasarkan pengamatan di lapangan yang dilakukan di jalan lintas Kecamatan Lembah Gumanti - Kecamatan Pantai Cermin dapat dilihat bahwa satuan bentuklahan lokasi penelitian adalah lereng kaki gunung api.

Kemiringan lereng berdasarkan pengamatan di lapangan bervariasi yaitu kelas III $40 \%$ dan kelas IV $43 \%$ dengan kriteria curam, dan sangat curam. Sebagaimana diketahui, Menurut Muchlis (2015) pada bagian atas lereng, terdapat lapisan tanah yang porus (mudah meloloskan air), menyebabkan air hujan akan mudah masuk ke dalam tanah.

Tanah daerah penelitian yaitu tanah Glei Humus. Berdasarkan hasil dari lapangan dapat dilihat keadaan tanah bervariasi. Struktur tanah terdiri atas butir tunggal, remah dan tunggal, konsistensi tanah adalah sangat gembur dan lepas-lepas, dan tekstur tanah pasir berdebu dan lempeng berpasir. Tanah sangat berpengaruh terhadap tingkat pengikisan karena komposisi tanah akan mempengaruhi daya serap air dan kepekaan terhadap pengikisan tanah diantarnya sifat-sifat tanah tersebut adalah tekstur tanah, kedalaman/solum tanah dan konsistensi tanah. Tekstur tanah merupakan perbandingan persentase pasir, debu, dan lempung. Banyak sedikitnya ukuran butir ketiga fraksi tersebut akan mempengaruhi respon terhadap masukan air. Tanah bertekstur pasir karena kekuatan agregatnya kurang kuat, maka akan mudah lepas apabila kelembaban bertambah.

Permeabilitas tanah juga sangat berpengaruh terhadap proses pengikisan tanah, semakin cepat air meluncur maka erosi yang terbawa akan semakin banyak sehingga dampak pengikisan dan longsor yang terjadi sangat besar. permeabilitas tanah di sepanjang jalan lintas Kecamatan Lembah Gumanti - Kecamatan Pantai 
Cermin sangat cepat, dimana dari 17,5-21 cm/jam dan cepat sebesar $7,09 \mathrm{~cm} /$ jam. Maka dari jumlah permeabilitas yang sangat tinggi maka tingkat laju erosi yang berdampak terhadap pengikisan tanah akan semakin besar.

Kedalaman muka air tanah lokasi penelitian berdasarkan hasil dari lapangan didominasi oleh muka air tanah yang dalam. Daerah penelitian yang merupakan dearah di sepanjang jalan lintas Kecamatan Lembah Gumanti Kecamatan Pantai Cermin mengakibatkan daerah memiliki kedalaman air tanah yang dalam hal ini disebabkan daerah yang berbukit bukit sehingga untuk mendapatkan air tanah harus melakukan penggalian kembali yang sangat dalam. Berdasarkan penjabaran tersebut dapat diketahui dengan kondisi daerah yang berbentuk perbukitan maka tingkat erosi dan pengikisan yang terjadi sangat besar. Hal ini juga disebabkan daerah yang berada kemiringan lereng yang tinggi mengakibatkan wilayah memiliki tingkat terjadinya longsor yang sangat tinggi.

Penggunaan lahan di daerah penelitian didominasi oleh tegalan/kebun campuran, semak belukar/alang-alang dan pemukiman. Penggunaan lahan sangat berpegaruh terhadap tingkat pengikisan yang terjadi pada daerah penelitian. Untuk penggunaan lahan yang berupa semak belukar/alang-alang tingkat bahayanya lebih tinggi dari pada penggunaan lahan lainnya karena berada pada daerah yang kemiringan lerengnya curam dan sangat curam. Rahman et al, (2014) menyampaikan bahwa selain iklim dan geotektonik, faktor manusia yaitu aktivitas manusia di atas lahan yang membebani lereng juga berkontribusi dalam terjadinya tanah longsor.

\section{B. Tingkat Bahaya Longsor}

Berdasarkan total pengharkatan seluruh variabel penelitian, maka dapat dibedakan menjadi 2 tingkatan yaitu tingkat bahaya longsor sedang: 1) terjadi pada satuan lahan dengan bentuklahan karst dengan kemiringan lereng $17^{\circ}$ dengan kriteria curam pada jenis batuan batu sabak campur batu gamping dengan penggunaan lahan tegalan/kebun campuran pada jenis tanah glei humus (K.III.Pcks.Tg.Glei) terdapat pada daerah Batang Hari, 2) Bentuklahan karst dengan kemiringan lereng $19^{\circ}$ dengan kriteria curam pada jenis batuan batu sabah campur batu gamping dengan penggunaan lahan hutan primer pada jenis tanah glei humus (K.III.PCks.Hp.Glei) terdapat pada daerah Aia Dingin, 3) Bentuklahan denudasional dengan kemiringan lereng $22^{\circ}$ dengan kriteria sangat 
curam pada jenis batuan batu sabah campur batu gamping dengan penggunaan lahan tegalan/kebun campuran pada jenis tanah glei humus (D.III.PCks.Tg.Glei) terdapat pada daerah Cubadak, 4) Bentuklahan denudasional dengan kemiringan lereng $20^{\circ}$ dengan kriteria curam pada jenis batuan batu granit dengan penggunaan lahan tegalan/kebun campuran pada jenis tanah glei humus (D.III.Mpip.Tg.Glei) terdapat pada daerah Lolo

Tingkat bahaya longsor tinggi terjadi pada satuan lahan dengan bentuklahan denudasional dengan kemiringan lereng $23^{\circ}$ dengan kriteria sangat curam pada jenis batuan batu sabak campur batu gamping dengan penggunaan lahan tegalan/kebun campuran pada jenis tanah glei humus (D.III.PCks.Hp.Glei). Tingkat bahaya longsor tinggi ini terdapat pada daerah Aia Ampu dengan penggunaan lahan permukiman yang diselingi dengan belukar/alang-alang, tegalan/kebun campuran dan pemukiman yang berada di pinggir jalan.

Semakin besar harkat struktur lapisan batuan, kemiringan lereng, panjang lereng, bentuk lereng, tekstur tanah, struktur tanah, konsistensi tanah, kedalaman muka air tanah, permeabilitas tanah, penggunaan lahan dan curah hujan maka akan semakin tinggi pula tingkat bahaya longsor di daerah penelitian. memberikan informasi bahwa pada tingkat bahaya longsor rendah memiliki tanah yang stabil dan tidak pernah atau jarang terjadi longsor kecuali pada tebing jalan dan sungai. Tingkat bahaya longsor sedang peluang terjadinya longsor 1 kali dalam 1 tahun pada lahan dengan kemiringan $>15 \%$ sedangkan tingkat bahaya longsor tinggi peluang terjadinya longsor 1-2 kali dalam 1 tahun. Seperti pada tabel 1 di bawah ini: 
Tabel 35. Hasil Analisis Tingkat Bahaya Longsor di Lokasi Penelitian

\begin{tabular}{|c|c|c|c|c|c|c|c|c|c|c|c|c|c|c|c|c|c|c|c|c|c|c|c|c|c|c|c|c|c|}
\hline \multirow[t]{4}{*}{ No } & \multirow{4}{*}{ Kode Satuan Lahan } & \multicolumn{26}{|c|}{ teristik Lahan } & \multirow{4}{*}{ Jumlah } & \multirow{3}{*}{ kriteria } \\
\hline & & \multirow{3}{*}{\multicolumn{2}{|c|}{$\begin{array}{l}\text { Iflim } \\
\mathrm{CH} \\
\end{array}$}} & \multirow{2}{*}{\multicolumn{2}{|c|}{$\begin{array}{l}\text { Geologi } \\
\text { SLB }\end{array}$}} & \multicolumn{10}{|c|}{ Geomorfologi } & \multicolumn{8}{|l|}{ Tanah } & \multirow{2}{*}{\multicolumn{2}{|c|}{\begin{tabular}{|l} 
hidrologi \\
KMA
\end{tabular}}} & \multirow{2}{*}{\multicolumn{2}{|c|}{\begin{tabular}{|l|}
$\begin{array}{l}\text { Penggunaan } \\
\text { lahan }\end{array}$ \\
P1
\end{tabular}}} & & \\
\hline & & & & & & BI & & SBI & & $\mathrm{KL}$ & & $\mathrm{BL}$ & & $\mathrm{PL}$ & & TT & & ST & & KT & & PT & & & & & & & \\
\hline & & & & $\mathrm{K}$ & S & $\mathrm{K}$ & S & $\mathrm{K}$ & S & $\mathrm{K}$ & S & $\mathrm{K}$ & S & $\mathrm{K}$ & S & $\mathrm{K}$ & $S$ & $\mathrm{~K}$ & $S$ & $\mathrm{~K}$ & S & $\mathrm{K}$ & S & $\mathrm{K}$ & S & $\mathrm{K}$ & is & & \\
\hline 1 & K.III.PCks.Tg.Glei & t & 0,6 & Miring & 0.18 & St & 0,2 & Sr & 0,05 & $\begin{array}{l}\text { III } \\
\left(17^{\circ}\right)\end{array}$ & 0,45 & Lurus & 0,06 & $\mathrm{p}$ & 0,18 & Sedang & 0,18 & Gumpal & 0,1 & \begin{tabular}{|l|} 
Sangat \\
Gembur \\
\end{tabular} & 0,06 & Sc & 0,15 & Dalam & 0,05 & $\mathrm{Tg}$ & 0,3 & 2,56 & Sedang \\
\hline 2 & K.III.PCks.Hp.Glei & t & 0,6 & $\begin{array}{l}\text { Miring } \\
\text { Bergelombang }\end{array}$ & 0.24 & St & 0,2 & Sr & 0,05 & $\begin{array}{l}\text { III } \\
\left(20^{\circ}\right)\end{array}$ & 0,45 & Cambung & 0,12 & 5 & 0,12 & Sedang & 0,18 & $\begin{array}{l}\text { Butir } \\
\text { Tungggal }\end{array}$ & 0,2 & \begin{tabular}{|l|} 
Lepas- \\
Lepas \\
\end{tabular} & 0,18 & c & 0,3 & Dalam & 0,05 & Blkr & 0,2 & 2,89 & Sedang \\
\hline 3 & D.IIIPCks.Hp.Glei & $t$ & 0,6 & $\begin{array}{l}\text { Miring } \\
\text { Bergelombang }\end{array}$ & 0,24 & St & 0,2 & Sr & 0,05 & $\left(22^{\circ}\right)$ & 0,6 & $\begin{array}{l}\text { Variasi } \\
\text { Cembung } \\
\text { Cekung }\end{array}$ & 0,24 & Sp & 0,24 & Kasar & 0,12 & $\begin{array}{l}\text { Butir } \\
\text { Tunggal }\end{array}$ & 0,2 & $\begin{array}{l}\text { Lepas- } \\
\text { Lepas }\end{array}$ & 0,18 & $\mathrm{Sc}$ & 0,15 & Dalam & 0,05 & Prmk & 0,4 & 3,27 & Tingsi \\
\hline 4 & D.III.PCks.Tg.Glei & t & 0,6 & Miring & 0,18 & St & 0,2 & Sr & 0,05 & $\begin{array}{l}\text { IV } \\
\left(23^{\circ}\right)\end{array}$ & 0,6 & Lurus & 0,06 & $\mathrm{p}$ & 0,18 & Sedang & 0,18 & Gumpal & 0,1 & $\begin{array}{l}\text { Sangat } \\
\text { Gembur }\end{array}$ & 0,06 & Sc & 0,15 & Dalam & 0,05 & $\mathrm{Tg}$ & 0,3 & 2,71 & Sedang \\
\hline 5 & D.IIIMpip.Tg.Glei & t & 0,6 & $\begin{array}{l}\text { Miring } \\
\text { Bergelombang }\end{array}$ & 0,24 & St & 0,2 & Sr & 0,05 & $\begin{array}{l}\text { III } \\
\left(16^{\circ}\right)\end{array}$ & 0,45 & Cekung & 0,18 & 5 & 0,12 & Kasar & 0,12 & $\begin{array}{l}\text { Butir } \\
\text { Tunggal }\end{array}$ & 0,2 & $\begin{array}{l}\text { Lepas- } \\
\text { Lepas }\end{array}$ & 0,18 & Sc & 0,15 & Dalam & 0,05 & $\mathrm{Tg}$ & 0,3 & 2,84 & Sedang \\
\hline
\end{tabular}

Sumber: Pengelola an Data Primer, (2017)

$\begin{aligned} \text { Keterangan: } \mathrm{CH} & \text { : Curah hujan } \\ \mathrm{SLB} & \text { : Strukturlapisan batuan } \\ \mathrm{Bl} & \text { : Bentuklahan } \\ \mathrm{SBL} & \text { : Satuan bentuklahan } \\ \mathrm{KL} & \text { : Kemininganlereng } \\ \mathrm{BL} & \text { : Bentuk lereng } \\ \mathrm{PL} & \text { :Panjanglereng } \\ \mathrm{TT} & \text { :Teksturtanah } \\ \mathrm{ST} & \text { : Strukturtanah } \\ \mathrm{St} & \text { :Solum tanah } \\ \mathrm{KT} & \text { : Konsistensi tanah } \\ \mathrm{PT} & \text { : Permeabilitas tanah } \\ \mathrm{KMA} & \text { : Kedalamanmuka airtanah } \\ \mathrm{Pl} & \text { : Penggunaan lahan }\end{aligned}$

$\mathrm{t} \quad$ : Tinggi

St :Sangat tingg

Sr : Sangat ren

p : Panjang

Sp : Sangat panjang

$\mathrm{Sc}$ : Sangat cepat

c : Cepat

$\mathrm{Tg}$ : Tegalan/kebuncampuran

Blkr : Belukar/alang-alang

$\mathrm{Ht}$ : Hutan 
PETA TINGKAT BAHAYA LONGSOR 


\section{PENUTUP}

\section{A. Simpulan}

1. Karakteristik lahan di lokasi penelitian menunjukkan daerah penelitian berpotensi terjadi bencana alam longsor. Karakteristik lahan memberikan pengaruh atau menunjukkan sifatsifat yang menjadi faktor pemicu terjadinya longsor di daerah penelitian, hal ini dibuktikan dari hasil pengamatan dan pengukuran sebagai berikut: a) iklim: curah hujan tinggi, b) geologi: struktur lapisan batuannya miring dan miring bergelombang, c) geomorfologi: kemiringan lereng yang sangat curam dengan lereng yang panjang dan bentuk lereng bervariasi, d) tanah: tekstur tanah sedang dengan konsistensi tanah sangat gembur, e) hidrologi: kedalaman muka air tanah tergolong dalam, f) penggunaan lahan: semak belukar/alang-alang dan tegalan/kebun campuran.

2. Berdasarkan total pengharkatan seluruh variabel penelitian, maka dapat dibedakan menjadi 2 tingkatan yaitu tingkat bahaya longsor terdapat pada daerah Batang Hari, Aia Dingin, Cubadak dan Lolo dan tingkat bahaya longsor tinggi terdapat pada daerah Aia Ampu dengan penggunaan lahan permukiman yang diselingi dengan belukar/alang-alang, tegalan /kebun campuran dan pemukiman yang berada di pinggir jalan.

\section{B. Saran}

1. Disarankan kepada penduduk yang berada di sepanjang jalan lintas Kecamatan Lembah Gumanti Kecamatan Pantai Cermin dan bagi pengendara kendaraan di sekitar satuan lahan yang mempunyai potensi bahaya longsor tinggi dan sedang supaya berhati-hati dan waspada jika terjadi longsor secara tiba-tiba.

2. Disarankan terhadap pemerintah daerah setempat agar dapat melakukan penanggulangan dan sosialisasi kepada penduduk setempat tentang bahaya longsor dan penataan ruang daerah lereng perbukitan yang dapat menjadi solusi untuk mengurangi terjadi longsor di jalan Kecamatan Lembah Gumanti - Kecamatan Pantai Cermin.

3. Penelitian harus dilakukan lebih lanjut lagi karena penilitian ini hanya sebatas mengetahui tingkat bahaya longsor.

\section{DAFTAR PUSTAKA}

BNPB, 2014. Tanah Longsor. http://dibi.bnpb.go.id/. Padang. Di akses pada Oktober 2016.

Chen, C. Y. dan Huang, W. L. 2013. Land Use Change and Landslide Characteristics Analysis for Community-Based Disaster Mitigation. Journal Environmental Monitoring and Assessment. Vol. 185(5), No. 4125-4139. 
Chen, Y., Zhou, H. dan Chen, Y. 2013. Adaptation Strategies of Desert Riparian Forest Vegetation in Response to Drought Stress. Journal Ecohydrology. Vol. 6(6), No. 956-973.

Forbes, K. dan Broadhead, J. 2013. Forests and Landslides: the Role of Trees and Forests in the Prevention of Landslides and Rehabilitation of LandslideAffected Areas in Asia. Bangkok: FAO.

Gorsevski, P. V., Gessler, P. E. dan Jankowski, P. 2003. Integrating a Fuzzy K-Means Classification and a Bayesian Approach for Spatial Prediction of Landslide Hazard. Journal of Geographical Systems. Vol. 5(3), No. 223-251.

Guillard, C., \& Zezere, J. 2012. Landslide Susceptibility Assessment and Validation in the Framework of Municipal Planning in Portugal: The Case of Loures Municipality. Journal Environmental Management. Vol. 50(4), No. 721-735.

Hermon, dedi. 2012. Mitigasi Bencana Hidrometeorologi. Padang: UNP Press.

Hua-xi, G. dan Kun-Long, Y. 2014. Study on Spatial Prediction and Time Forecast of Landslide. Journal Natural Hazard. Vol. 70(3), No. 1735-1748.

Karim, Sutarman. et al. 2012. Panduan KKL Geografi Non
Kependidikan, Padang: Jurusan Geografi UNP

Kim, H. G., Lee, D. K., Park, C., Kil, S., Son, Y., \& Park, J. H. 2015. Evaluating Landslide Hazards Using RCP 4.5 and 8.5 Scenarios. Journal Environmental Earth Sciences. Vol. 73(3), No. 1385-1400.

Lepore, C., Arnone, E., Noto, L. V., Sivandran, G., \& Bras, R. L. 2013. Physically Based Modeling of Rainfall-Triggered Landslides: a Case Study in the Luquillo Forest, Puerto Rico. Journal Hydrology and Earth System Sciences, Vol. 17(9), No. 3371-3387.

Muchlis. 2015. Interpretasi Potensi Massa Longsoran Dengan Metoda Geolistrik (Studi Kasus Daerah Gayo Lues). Jurnal Natural, Vol. 15(1), No. 16-18.

Pemerintah Republik Indonesia. 2007. Undang-Undang No. 24 Tahun 2007 tentang Penanggulangan Bencana. Jakarta: DPR RI.

Pereira, S. D. S., Zêzere, J. L. G. M. D., \& Bateira, C. 2013. Technical Note: Assessing Predictive Capacity and Conditional Independence of Landslide Predisposing Factors for Shallow Landslide Susceptibility Models. Journal Natural Hazards and Earth System Sciences. Vol. 12(2012), No. 979-988.

Ponziani, F., Pandolfo, C., Stelluti, M., Berni, N. Brocca, L. \& Moramarco, T., 2012. 
Assessment of Rainfall Thresholds and Soil Moisture Modeling for Operational Hydrogeological Risk Prevention in the Umbria Region (Central Italy). Landslides. Vol. 9(2), No. 229237.

Putra, A., Triyatno, Syarief, A., \& Hermon, D., 2018. Penilain Erosi Berdasarkan Metode USLE dan Arahan Konservasi Pada DAS Air Dingin Bagian Hulu di Kota Padang. Jurnal Geografi. Vol. 10(1), No. 1-13.

Rahman, M. W., et al., 2014. Status Kualitas Air dan Upaya Konservasi Sumberdaya Lahan di DAS Citarum Hulu, Kabupaten Bandung. Jurnal Pengelolaan Sumberdaya Alam dan Lingkungan. Vol. 4(1), No. 24-34.

Sipayung, S. B., et al., 2014. Pengembangan Model Persamaan Empiris Dalam Memprediksi Terjadinya Longsor di Daerah Aliran Sungai (DAS) Citarum (Jawa Barat) Berbasis Data Satelit TRMM. Jurnal Sains Dirgantara. Vol. 12(1), No. 12-21. 